\title{
Mediators of Intergenerational Continuity of Child Maltreatment among Japanese Mothers
}

\author{
Takeo Fujiwara $^{1} \&$ Makiko Okuyama ${ }^{2}$ \\ ${ }^{1}$ Department of Social Medicine, National Research Institute for Child Health and Development, Setagaya-ku, \\ Tokyo, Japan \\ ${ }^{2}$ Department of Psychosocial Medicine, National Center for Child Health and Development, Setagaya-ku, Tokyo, \\ Japan \\ Correspondence: Takeo Fujiwara, Department of Social Medicine, National Research Institute for Child Health \\ and Development, 2-10-1Okura, Setagaya-ku, Tokyo 157-8535 Japan. Tel: 81-3-3417-2663. E-mail: \\ fujiwara-tk@ncchd.go.jp
}

Received: June 24, 2013 Accepted: July 9, 2013 Available online: July 24, 2013

doi:10.11114/ijsss.v1i2.77

URL: http://dx.doi.org/10.11114/ijsss.v1i2.77

\begin{abstract}
The aim of this study is to test the hypothesis that domestic violence (DV) or mental health symptoms might mediate the intergenerational continuity of child maltreatment among mothers in Japan. A self-administered questionnaire survey was conducted among a sample of mothers $(\mathrm{N}=304)$ and their children $(\mathrm{N}=498)$ in Japan to assess the mothers' childhood abuse history, DV experiences, and current mental health symptoms, along with their maltreatment behaviors toward their children after moving into Mother-Child Homes, similar to the DV shelters. We found that mental health symptoms, but not DV, mediated the link between childhood abuse history and child maltreatment. Treating mental symptoms, especially dissociated and depressive symptoms, might be the effective way to break the cycle of child maltreatment.
\end{abstract}

Keywords: Child abuse history, Domestic violence, Intergenerational transmission, Mental health

List of abbreviations: childhood abuse history: childhood abuse history, DV: domestic violence, GEE: generalized estimating equation

\section{Introduction}

One of the most well-known risk factors of child maltreatment is the history of childhood abuse among the parents of an ill-treated child (Steele \& Pollack, 1968; Widom, 1989b). Despite this, previous reviews have reported that the intergenerational continuity of child abuse is somewhat inconclusive, owing to methodological issues (Ertem, Leventhal, \& Dobbs, 2000). In addition, most of the research studies that are the basis for these reviews were implemented in Western society; few studies have reported the intergenerational continuity of child abuse in Asian society.

Despite the popular theory of the intergenerational continuity of child abuse, little research disentangles the mediators of the intergenerational continuity of child maltreatment. For example, although the percentage of parents who abuse their children was higher among those who had been abused in childhood than in non-abused parents, it was seen that a majority of abused parents did not abuse their children (Kaufman \& Zigler, 1987; Widom, 1989a). Thus, it is essential to conduct a study that reveals the mediators of the intergenerational continuity of child maltreatment. One possible mechanism is the deterioration of the mental health of the parents. For example, reports have shown that parents with childhood abuse history were more likely to exhibit dissociation symptoms than those without childhood abuse history (Egeland \& Susman-Stillman, 1996). As childhood abuse history can lead to other mental health symptoms such as depression or traumatic symptoms (Horwitz, Widom, McLaughlin, \& White, 2001; Widom, DuMont, \& Czaja, 2007), further research warrants a wider assessment of the mental health symptoms of parents with and without childhood abuse history. In addition, because each type of childhood abuse history (i.e., physical, psychological, and sexual abuse and neglect) and mental health symptom might differently contribute to each type of child maltreatment (Briere \& Runtz, 1988; Newcomb \& Locke, 2001; Rieker \& Carmen, 1986), and research should be conducted to illustrate 
the impact of childhood abuse history and mental health symptoms on each type of child maltreatment.

If mental health symptoms can be mediators of child maltreatment by parents with childhood abuse history, the existence of domestic violence (DV) should also be included in the analysis model because individuals with childhood abuse history have a higher propensity for involvement with violent partners (Fantuzzo, Boruch, Beriama, Atkins, \& Marcus, 1997; Ross, 1996; Tajima, 2000). Few studies have simultaneously investigated the impact of childhood abuse history and DV on child maltreatment behaviors.

In addition, previous research on the intergenerational continuity of child maltreatment assessed childhood abuse history and current child maltreatment as dichotomous variables, which result in information bias because mild child maltreatment cases can be labeled as either maltreated or non-maltreated cases depending on the cut-off (Newcomb \& Locke, 2001). Further, in the case of the dichotomous model, poly-victimization cases (e.g., being a victim of both physical abuse and neglect) and single victimization cases are treated in the same group. Recent research reveals that poly-victimization has a stronger impact on the later life of the victims (Edwards, Holden, Felitti, \& Anda, 2003; Finkelhor, Ormrod, \& Turner, 2007). Thus, child maltreatment should be treated as a spectrum wherein poly-victimization should be taken into account.

In Japan, mothers, who are victims of DV or want to separate from their husbands or partners who abuse their children or other reasons, are supported by Mother-Child Homes where they can live with their children. This setting gives us a platform to assess the impact of childhood abuse history and DV on the different types of maltreatment (physical and psychological abuse and neglect) inflicted on the children by their mothers and confirm the impacts of childhood abuse history and DV that persist after separating from a violent husband or partner.

Thus, the purpose of this study is to illustrate the impact of each type of childhood abuse history, the experience of DV, and mental symptoms of the mother in each type of maternal child maltreatment among mothers who separated from violent husbands or partners in Japan to test the hypothesis that mental health symptoms mediate the intergenerational continuity of child maltreatment.

\section{Methods}

\subsection{Sample}

The details of this study procedure were previously described (Fujiwara, Okuyama, Izumi, \& Osada, 2010). The study was set in all the Mother-Child Homes in Japan $(\mathrm{N}=83)$, which include a welfare facility and where mothers and children who have suffered from family problems (e.g., DV, child abuse from husband or partner of mother, or single mother with financial problems) can stay and receive help in becoming self-sufficient. All the mothers $(\mathrm{N}=1,369)$ at the mother-child homes, including those who were residing for reasons other than child abuse and domestic violence, were invited to participate in the study, and questionnaires were posted to the 421 mothers who agreed to participate (30.8\%) in December, 2005. A total of 340 mothers completed the survey $(80.1 \%)$. In addition, the mothers were asked to respond to the questionnaires per child, i.e., if a mother had two children, she was asked to complete two questionnaires each pertaining to one child. In total, 665 children's questionnaires were collected. The child questionnaires completed by the mothers were labeled with a maternal ID for further reference while merging them with the mothers' questionnaires. In order to maintain anonymity, the respondents were instructed to work on the survey alone, which required no formal consent; thus, no support was provided in the completion of the survey.

\subsection{Measurements}

\subsubsection{Childhood Abuse History}

The childhood abuse history was assessed using the following seven questions: (1) I was a victim of violence by my parents (including step-parents); (2) I was ignored or refused attention by my parents; (3) My parents insulted me verbally; (4) My parents were so severely violent with me that I required hospital treatment; (5) I have been deprived of food or warm clothes; (6) I have experienced forced sexual contact by a parent (sexual contact includes sexual intercourse, petting, exposure of genitals, and taking naked pictures); and (7) I have experienced forced sexual contact by an adult other than a parent. Each question was answered on a 1-4 Likert scale, ranging from $1=$ not at all, $2=$ rarely, $3=$ sometimes, to $4=$ frequently. These questions were created on the basis of the Childhood Trauma Questionnaire (CTQ) (Bernstein et al., 1994) but modified to suit the Japanese language and were minimized to only 7 questions to reduce the burden on the respondents. In order to capture the mild to severe form of childhood abuse, 5 physical abuse questions, 6 neglect questions, 12 psychological abuse questions, and 6 sexual abuse questions from the CTQ were condensed to 2, 1, 2, and 2 questions, respectively. These questions were the result of focus group discussions among experienced Japanese 
child abuse specialists (authors of this paper, MO and TF), to ensure that the questions were culturally acceptable (e.g. A question such as neglect due to the parents' use of illegal drugs was omitted because illegal drug use by parents is quite rare in Japan.). The total history of childhood abuse was calculated by summing the scores of the responses to these 7 questions, and used as continuous outcome variable. Cronbach's alpha for this scale is 0.78 .

Furthermore, the childhood abuse history was subdivided into physical abuse, neglect, psychological abuse, and sexual abuse. Survey questions 1 and 4 pertained to physical abuse, 5 to neglect, 2 and 3 to psychological abuse, and 6 and 7 to sexual abuse. If each subscale had 2 questions, the responses for each item were added.

\subsubsection{Experience of DV}

Experience of DV was assessed using the following four questions: (1) My husband or partner was violent enough to cause me injury, (2) My husband or partner insulted me strongly enough to cause psychological harm, (3) I perceived a strong threat from my husband or partner, and (4) My husband or partner forced me to have sexual contact. Each question was answered on a 1-4 Likert scale, ranging from $1=$ not at all, $2=$ rarely, $3=$ sometimes, to $4=$ frequently. These questions were created on the basis of the Index of Spouse Abuse (Hudson \& McIntosh, 1981) but were modified to suit the Japanese language and minimized to 4 questions to reduce the burden on the respondents. In order to capture the severe form of domestic violence (e.g. injury-causing violence and not just a slap or punch), 11 spousal physical abuse questions (including 6 questions on physical assault; 4, on a partner's threat towards his wife; and 1, on forced sexual contact) and 19 non-physical abuse questions in the ISA were condensed to 4 questions: one each on physical assault, psychological insult, threat, and forced sexual contact. These questions were also the result of the focus group discussions mentioned above. A summation of the scores of the responses to these questions was used as a scale to indicate the respondents' experiences of DV. Cronbach's alpha for this scale is 0.86 .

\subsubsection{Mother's Mental Health Symptoms}

The mothers' current mental health symptoms were assessed by self-administered questionnaire and classified as dissociated, depressive, or traumatic symptoms. The questions used in this assessment were developed on the basis of the symptoms list in the DSM-IV and from focus group discussions between an experienced Japanese child psychiatrist and a psychologist. Questions for this assessment were created on the basis of the DSM-IV and have been previously shown (Fujiwara, et al., 2010). Symptoms of dissociation observed in the mothers' caretaking of the children were assessed by a summation of responses to 10 questions answered using a 1-4 Likert scale, ranging from $1=$ not at all, $2=$ rarely, $3=$ sometimes, to $4=$ frequently. Similarly, depressive and traumatic symptoms were assessed using 11 and 8 questions respectively. Cronbach's alpha for the dissociated, depressive, and traumatic symptom assessments are $0.82,0.88$, and 0.85 , respectively.

\subsubsection{Child Maltreatment}

Three subtypes of child maltreatment (physical and psychological abuse and neglect) were queried when the mothers were in the current living environment (i.e., after separating from husband or partner and living in the Mother-Child Home). Sexual abuse was not measured as the subjects were mothers and few mothers indulge in sexual abuse. Physical abuse was assessed by asking the mothers about their experience of beating and kicking their children. Psychological abuse was assessed by asking them about their experience of verbal abuse (speaking to children with harmful words). Neglect was assessed by asking them their experience of (1) not providing the necessary care for the child's survival, such as lack of provision of meal or clothes and (2) not playing or enjoying talking with the child (reverse coded). Each experience was assessed by 1-4 Likert scale, ranging from $1=$ not at all, $2=$ rarely, $3=$ sometimes to $4=$ frequently. To obtain the neglect score, a summation of the responses to the two questions was used. These questions were developed on the basis of the Japanese version of Maltreatment (Center for Child Abuse Prevention, 1999), which originally comprises 17 items but has been modified to a questionnaire consisting of only 5 questions to reduce the burden on the respondents.

\subsubsection{Covariates}

Potential confounders were assessed in the questionnaire. For each mother, her age, current marital status, current working status, length of stay in the facility, professional support (i.e., medical or legal support including psychological therapy) were assessed. For each child, the age, sex, birth order, whether they were the mother's biological child, medical treatment, and other welfare/educational support were included. Details of the items used to assess these covariates are shown in Table 1. 
Table 1. Characteristics of sample

\begin{tabular}{|c|c|c|c|}
\hline & & Mean (SD) or N $(\%)$ & range \\
\hline \multicolumn{4}{|l|}{ Family characteristics $(N=304)$} \\
\hline \multicolumn{2}{|l|}{ Mother's age (years) } & $35.8(7.1)$ & $19-56$ \\
\hline \multicolumn{2}{|l|}{ Husband or partner's age (years) } & $39.6(9.7)$ & $21-70$ \\
\hline \multirow[t]{3}{*}{ Marital status } & Married & $40(13.3)$ & \\
\hline & Lived together, not married & $39(12.9)$ & \\
\hline & Divorced & $223(73.8)$ & \\
\hline \multirow[t]{4}{*}{ Maternal working status } & vocational training & $12(4.0)$ & \\
\hline & working part-time & $156(51.3)$ & \\
\hline & working full-time & $88(29.0)$ & \\
\hline & unemployed & $48(15.8)$ & \\
\hline \multicolumn{2}{|c|}{ Length of stay in Mother-Child Home (years) } & $2.39(2.49)$ & $0.08-18$ \\
\hline \multirow[t]{2}{*}{ Professional support } & Yes & $105(35.5)$ & \\
\hline & No & $191(64.5)$ & \\
\hline \multirow{3}{*}{$\begin{array}{l}\text { Reason for staying at Mother-Child } \\
\text { Home (multiple choice) }\end{array}$} & Domestic Violence & $300(60.2)$ & \\
\hline & Abuse to child(ren) by male partner & $116(23.3)$ & \\
\hline & Other & $244(49.0)$ & \\
\hline \multicolumn{4}{|l|}{ Child characteristics $(N=498)$} \\
\hline Children's age & & $7.8(4.3)$ & $0.1-19.6$ \\
\hline \multirow[t]{2}{*}{ Sex } & Boy & $253(50.9)$ & \\
\hline & Girl & $244(49.1)$ & \\
\hline \multirow[t]{5}{*}{ Birth order } & $1 \mathrm{st}$ & $302(60.6)$ & \\
\hline & $2 \mathrm{nd}$ & $139(27.9)$ & \\
\hline & $3 \mathrm{rd}$ & $44(8.8)$ & \\
\hline & 4th & $10(2.0)$ & \\
\hline & 5 th & $3(0.6)$ & \\
\hline \multirow[t]{2}{*}{ Biological child } & Yes & $497(99.8)$ & \\
\hline & No & $1(0.2)$ & \\
\hline \multirow[t]{2}{*}{ Receiving medical treatment } & Yes & $73(14.7)$ & \\
\hline & No & $425(85.3)$ & \\
\hline \multirow{2}{*}{$\begin{array}{l}\text { Receiving other professional/welfare } \\
\text { support }\end{array}$} & Yes & $92(18.5)$ & \\
\hline & No & $406(81.5)$ & \\
\hline
\end{tabular}

\subsection{Institutional Review Board (IRB) Approval}

The IRB at the National Center for Child Health and Development approved this study. The return of a completed questionnaire was accepted as the respondent's consent to participate in the study; therefore, the IRB approved the present study without any prior formal consent from the participants.

\subsection{Analysis}

For the analysis, because the childhood abuse history, DV, mental symptoms, and child maltreatment after separating from a violent husband or partner were major explanatory and outcome variables, samples of those individuals who met these variables were included for further analysis (mother's $\mathrm{N}=304$ (89\%), children's $\mathrm{N}=$ $498(75 \%))$. In order to help with the interpretation of the regression coefficient, childhood abuse history, DV, mental symptoms, and child maltreatment scores were converted to a score in the range of 0-10.

First, the bivariate association of childhood abuse history (including subtypes), DV, and mental health symptoms with child maltreatment was estimated by linear regression using a generalized estimating equation (GEE), which adjusts for the clustering of outcomes among siblings, adjusted for the mother's age, child's age and sex, birth order, medical treatment, welfare/educational support status, marital status, working status, length of stay, and professional support for mother.. Then, as Model 1, the independent association of childhood abuse history (including subtypes), DV, and mental health symptoms with child maltreatment was estimated by a linear regression of GEE. Mental health symptoms could not be included in one model, owing to a high correlation among the symptoms $(0.50-0.74)$. Further, subtypes of childhood abuse history (i.e., childhood physical, psychological, sexual abuse and neglect), DV, and mental health symptoms were included in the same model (Model 2), and coefficients were calculated by a linear regression of GEE. Thus, the model 1 and model 2 can be written as follows:

$$
\text { Model 1: } \mathrm{Y}_{\mathrm{ij}}=\beta_{0}+\beta_{1} \mathrm{X}_{\mathrm{ij}}^{1}+\beta_{2} \mathrm{~W}_{\mathrm{ij}}+\beta_{3} \mathrm{Z}_{\mathrm{ij}}+\text {-ovariates }_{\mathrm{ij}}
$$




$$
\text { Model 2: } Y_{\mathrm{ij}}=\beta{ }^{\prime}{ }_{0}+\beta{ }_{1}{ }_{1} \mathrm{X}_{\mathrm{ij}}+\beta{ }_{2} \mathrm{~W}_{\mathrm{ij}}+\beta{ }{ }_{3} \mathrm{Z}_{\mathrm{ij}}+\text { covariates }_{\mathrm{ij}}
$$

Where $\mathrm{Y}$ denotes child maltreatment scores (i.e. child physical abuse, psychological abuse or neglect scores), $\mathrm{X}^{1}$ denotes childhood abuse history total score, $X^{2}$ denotes subtypes of childhood abuse history (i.e. childhood physical, psychological, sexual abuse or neglect), W denotes DV score, Z denotes mental health symptoms scores (dissociation, depression, or trauma symptoms), and covariates included mother's age, child's age and sex, birth order, medical treatment, welfare/educational support status, marital status, working status, length of stay, and professional support for mother, let the first subscript, i, represent the family ID, and let the second subscript $\mathrm{j}$ represent order of sibling in the family.

In the comparison between the bivariate Models 1 and 2, it is possible to infer whether mental health symptoms mediate the impact of childhood abuse history or DV on child maltreatment using the mental health symptoms; however, it is unclear whether or not the mediation effect is significant. Thus, the statistical significance of mental health symptoms as partial mediators was tested using the Sobel test (Baron \& Kenny, 1986). Multicollinearity test was performed and condition numbers ranged 28.7-35.0. Skewness-Kurtosis (Jarque-Bera) test was also performed and p-values ranged $<0.01-0.41$. Homoscedasticity was confirmed by Breusch-Pagan/ Cook-Weisberg test (all $\mathrm{p}<0.05$ ). Statistical analyses were performed by Stata version 10 .

\section{Results}

The sample characteristics are shown in Table 1. For the mothers' characteristics, the mean age was 35.8 years old $(S D=7.1)$, with a range of $19-56$ years. A majority of the sample $(72.7 \%)$ had divorced their husbands. The mean duration of stay in the Mother-Child Home was 2.39 years $(S D=2.49)$, with a maximum of 18 years. In the case of the children, the mean age was 7.8 years $(S D=4.5)$, from a one-month old infant to around a 20-year-old adolescent.

Results of the regression coefficients of childhood abuse history, DV, and mental health symptoms on child physical abuse are shown in Table 2. Interestingly, the impact of DV was not significant even in the bivariate model. The total childhood abuse history score and the dissociated and depressive symptoms remain independently and significantly associated with child physical abuse, even after separation from the husband or partner and living in a Mother-Child Home. This remains constant even after adjusting the current marital status, working status, length of stay, and professional support. The Sobel test confirmed that dissociated $(z=2.09, p=$ $0.037)$ and depressive symptoms $(z=2.14, p=0.032)$ mediated the impact of childhood abuse history on current child physical abuse. Among the subtypes of childhood abuse history, only the childhood physical abuse history showed an independent association with current child physical abuse, after adjusting other subtypes of childhood abuse history, DV, and mental symptoms. As the childhood physical abuse history was not associated with the dissociated or depressive symptoms, these symptoms were not specifically considered to mediate the impact of childhood physical abuse history. Dissociated symptoms and the childhood physical abuse history score showed a strong association with current child physical abuse, wherein a $10 \%$ increase in these scores showed a $4 \%$ and $2 \%$ increase in the current child physical abuse score respectively.

Table 2. Regression coefficient of maternal child abuse history, domestic violence, and mental health problems on child physical abuse after moving into Mother-Child Home by GEE analysis

\begin{tabular}{|c|c|c|c|c|c|c|c|c|c|c|c|c|c|c|c|c|c|c|c|c|c|}
\hline & \multicolumn{3}{|c|}{ Bivariate } & \multicolumn{9}{|c|}{ Model 1} & \multicolumn{9}{|c|}{ Model 2} \\
\hline & $\beta$ & $S E$ & $p$ & $\beta$ & $S E$ & $p$ & $\beta$ & $S E$ & $p$ & $\beta$ & $S E$ & $p$ & $\beta$ & $S E$ & $p$ & $\beta$ & $S E$ & $p$ & $\beta$ & $S E$ & $p$ \\
\hline \multicolumn{22}{|l|}{ Childhood abuse history } \\
\hline Total score & 0.20 & 0.07 & 0.003 & 0.15 & 0.07 & 0.031 & 0.16 & 0.07 & 0.024 & 0.18 & 0.07 & 0.009 & & & & & & & & & \\
\hline Physical abuse & 0.24 & 0.06 & $<0.001$ & & & & & & & & & & 0.23 & 0.08 & 0.004 & 0.23 & 0.08 & 0.005 & 0.24 & 0.08 & 0.004 \\
\hline Psychological abuse & 0.08 & 0.04 & 0.037 & & & & & & & & & & -0.07 & 0.05 & 0.130 & -0.04 & 0.05 & 0.395 & -0.03 & 0.05 & 0.490 \\
\hline Neglect & 0.11 & 0.05 & 0.027 & & & & & & & & & & 0.05 & 0.06 & 0.439 & 0.03 & 0.06 & 0.600 & 0.03 & 0.06 & 0.583 \\
\hline Sexual abuse & 0.07 & 0.08 & 0.370 & & & & & & & & & & 0.04 & 0.08 & 0.595 & -0.01 & 0.08 & 0.862 & -0.02 & 0.08 & 0.810 \\
\hline Domestic violence & 0.02 & 0.04 & 0.594 & 0.01 & 0.04 & 0.737 & 0.007 & 0.04 & 0.847 & -0.0007 & 0.04 & 0.985 & 0.01 & 0.04 & 0.729 & 0.009 & 0.04 & 0.806 & -0.0004 & 0.04 & 0.993 \\
\hline \multicolumn{22}{|l|}{ Mental health symptoms } \\
\hline Dissociated symptoms & 0.43 & 0.07 & $<0.001$ & 0.41 & 0.07 & $<0.001$ & & & & & & & 0.42 & 0.07 & $<0.001$ & & & & & & \\
\hline Depressive symptoms & 0.17 & 0.05 & 0.001 & & & & 0.14 & 0.05 & 0.007 & & & & & & & 0.14 & 0.05 & 0.006 & & & \\
\hline Traumatic symptoms & 0.10 & 0.05 & 0.066 & & & & & & & 0.06 & 0.05 & 0.242 & & & & & & & 0.08 & 0.05 & 0.166 \\
\hline Wald chi-square & & & & 85.3 & & & 56.1 & & & 49.4 & & & 94.0 & & & 62.1 & & & 55.4 & & \\
\hline
\end{tabular}

All independent and dependent variables ranged from 0-10.

Mother's age, marital status, working status, length of stay, receiving professional support, child's age, child's sex, child's birth order, medical treatment, and welfare/educational support status were adjusted.

A similar association was observed for current child psychological abuse (Table 3). DV was not associated with child psychological abuse. Moreover, the total score of childhood abuse history and the dissociated and 
depressive symptoms showed independent and significant associations. The Sobel test confirmed that dissociated $(z=2.14, p=0.032)$ and depressive symptoms $(z=2.86, p=0.004)$ mediated the impact of childhood abuse history on current child psychological abuse. Among the subtypes of childhood abuse history, childhood physical abuse, but not psychological abuse, was independently associated with current child psychological abuse. As the childhood physical abuse history was not associated with dissociated or depressive symptoms, these symptoms were not considered to mediate the impact of childhood psychological abuse history. Interestingly, having a childhood sexual abuse history was inversely and significantly associated with child psychological abuse after adjusting the DV and depressive or traumatic symptoms. The dissociated and depressive symptoms and childhood physical abuse history score showed a strong association with current child psychological abuse wherein $10 \%$ increase of these scores showed a $5 \%, 2 \%$, and $2 \%$ increase in the current child psychological abuse scores, respectively.

Table 3. Regression coefficient of maternal child abuse history, domestic violence, and mental health problems on child psychological abuse after moving into Mother-Child Home by GEE analysis

\begin{tabular}{|c|c|c|c|c|c|c|c|c|c|c|c|c|c|c|c|c|c|c|c|c|c|}
\hline & \multicolumn{3}{|c|}{ Bivariate } & \multicolumn{9}{|c|}{ Model 1} & \multicolumn{9}{|c|}{ Model 2} \\
\hline & $\beta$ & $S E$ & $p$ & $\beta$ & $S E$ & $p$ & $\beta$ & $S E$ & $p$ & $\beta$ & $S E$ & $p$ & $\beta$ & $S E$ & $p$ & $\beta$ & $S E$ & $p$ & $\beta$ & $S E$ & $p$ \\
\hline \multicolumn{22}{|l|}{ Childhood abuse history } \\
\hline Total score & 0.22 & 0.07 & 0.002 & 0.15 & 0.07 & 0.025 & 0.14 & 0.07 & 0.037 & 0.20 & 0.07 & 0.005 & & & & & & & & & \\
\hline Physical abuse & 0.25 & 0.06 & $<0.001$ & & & & & & & & & & 0.23 & 0.08 & 0.004 & 0.22 & 0.08 & 0.005 & 0.24 & 0.08 & 0.004 \\
\hline Psychological abuse & 0.12 & 0.04 & 0.001 & & & & & & & & & & 0.02 & 0.05 & 0.614 & 0.05 & 0.05 & 0.312 & 0.08 & 0.05 & 0.129 \\
\hline Neglect & 0.07 & 0.05 & 0.144 & & & & & & & & & & -0.05 & 0.06 & 0.390 & -0.07 & 0.06 & 0.252 & -0.06 & 0.06 & 0.299 \\
\hline Sexual abuse & -0.05 & 0.08 & 0.525 & & & & & & & & & & -0.10 & 0.08 & 0.223 & -0.16 & 0.08 & 0.042 & -0.17 & 0.08 & 0.035 \\
\hline Domestic violence & 0.03 & 0.04 & 0.511 & 0.02 & 0.04 & & 0.616 & 0.04 & & 0.806 & 0.04 & 0.902 & 0.02 & 0.04 & & 0.557 & 0.04 & & 0.685 & 0.04 & \\
\hline \multicolumn{22}{|l|}{ Mental health symptoms } \\
\hline Dissociated symptoms & 0.52 & 0.07 & $<0.001$ & 0.50 & 0.07 & $<0.001$ & & & & & & & 0.48 & 0.07 & $<0.001$ & & & & & & \\
\hline Depressive symptoms & 0.27 & 0.05 & $<0.001$ & & & & 0.24 & 0.05 & $<0.001$ & & & & & & & 0.23 & 0.05 & $<0.001$ & & & \\
\hline Traumatic symptoms & 0.09 & 0.05 & 0.077 & & & & & & & 0.06 & 0.05 & 0.299 & & & & & & & 0.05 & 0.05 & 0.349 \\
\hline Wald chi-square & & & & 110.6 & & & 77.1 & & & 53.3 & & & 120.7 & & & 90.5 & & & 66.7 & & \\
\hline
\end{tabular}

All independent and dependent variables ranged from 0-10.

Mother's age, marital status, working status, length of stay, receiving professional support, child's age, child's sex, child's birth order, medical treatment, and welfare/educational support status were adjusted.

Table 4 shows the regression coefficients of childhood abuse history, DV, and mental health symptoms on child neglect. childhood abuse history or DV were not associated with child neglect. Among the mental health symptoms, the dissociated and depressive symptoms, but not the traumatic symptoms, were associated with current child neglect. A $10 \%$ increase in the dissociated symptom score increased $2 \%$ of the child neglect score.

Table 4. Regression coefficient of maternal child abuse history, domestic violence, and mental health problems on child neglect after moving into Mother-Child Home by GEE analysis

\begin{tabular}{|c|c|c|c|c|c|c|c|c|c|c|c|c|c|c|c|c|c|c|c|c|c|c|}
\hline & \multicolumn{3}{|c|}{ Bivariate } & \multicolumn{9}{|c|}{ Model 1} & \multicolumn{10}{|c|}{ Model 2} \\
\hline & $\beta$ & $S E$ & $p$ & $\beta$ & $S E$ & $p$ & $\beta$ & $S E$ & $p$ & $\beta$ & $S E$ & $p$ & $\beta$ & & $S E$ & $p$ & $\beta$ & $S E$ & $p$ & $\beta$ & $S E$ & $p$ \\
\hline \multicolumn{23}{|l|}{ Childhood abuse history } \\
\hline Total score & 0.03 & 0.05 & 0.496 & 0.001 & 0.04 & 0.984 & 0.003 & 0.05 & 0.942 & 0.01 & 0.05 & 0.805 & & & & & & & & & & \\
\hline Physical abuse & 0.02 & 0.04 & 0.714 & & & & & & & & & & -0.01 & & 0.05 & 0.807 & -0.01 & 0.05 & 0.798 & -0.01 & 0.06 & 0.904 \\
\hline Psychological abuse & 0.03 & 0.02 & 0.227 & & & & & & & & & & 0.03 & & .03 & 0.387 & 0.04 & 0.03 & 0.225 & 0.04 & 0.03 & 0.216 \\
\hline Neglect & -0.01 & 0.03 & 0.754 & & & & & & & & & & -0.04 & & .04 & 0.313 & -0.05 & 0.04 & 0.246 & -0.05 & 0.04 & 0.255 \\
\hline Sexual abuse & -0.005 & 0.05 & 0.930 & & & & & & & & & & 0.01 & & .05 & 0.850 & -0.01 & 0.05 & 0.820 & -0.01 & 0.06 & 0.792 \\
\hline Domestic violence & 0.02 & 0.03 & 0.478 & 0.02 & 0.02 & & 0.487 & 0.02 & 0.55 & 0.0 & & & 0.02 & 0.02 & & & & 02 & & & & \\
\hline \multicolumn{23}{|l|}{ Mental health symptoms } \\
\hline Dissociated symptoms & 0.20 & 0.05 & $<0.001$ & 0.20 & 0.05 & $<0.001$ & & & & & & & 0.19 & & 0.05 & $<0.001$ & & & & & & \\
\hline Depressive symptoms & 0.08 & 0.03 & 0.011 & & & & 0.08 & 0.03 & 0.016 & & & & & & & & 0.08 & 0.03 & 0.020 & & & \\
\hline Traumatic symptoms & 0.07 & 0.03 & 0.052 & & & & & & & 0.06 & 0.04 & 0.084 & & & & & & & & 0.06 & 0.04 & 0.113 \\
\hline Wald chi-square & & & & 43.1 & & & 31.4 & & 28.5 & & & & 44.6 & & & & & & & & & \\
\hline
\end{tabular}

All independent and dependent variables ranged from $0-10$.

Mother's age, marital status, working status, length of stay, receiving professional support, child's age, child's sex, child's birth order, medical treatment and welfare/educational support status were adjusted..

\section{Discussion}

This study revealed the intergenerational continuity of child physical and psychological abuse, but not neglect, in Japan. After separation from the violent husband or partner and living in the Mother-Child Home, the impact of 
DV on child maltreatment was not observed. In addition, mental health symptoms, especially dissociated and depressive symptoms, showed strong impacts on child maltreatment, and were considered to mediate the impact of childhood abuse history.

To the best of our knowledge, this study is the first to have confirmed the intergenerational continuity of child physical abuse in Japan, although this phenomenon has been reported in previous studies from western societies (Brown, Cohen, Johnson, \& Salzinger, 1998; Crouch, Milner, \& Thomsen, 2001). Moreover, the current study is the first to report the specific types of childhood abuse (i.e., physical or psychological abuse) history that beget the same type of child abuse in the next generation, although neglect did not beget neglect. The differential impacts of subtypes of child maltreatment have been pointed out in previous literature (Knutson, 1995; Newcomb \& Locke, 2001; Widom, 1989b), but few studies have conducted the analysis using the subtypes of child maltreatment, mainly owing to limited power.

The specific subtype of the intergenerational continuity of child maltreatment can be explained by the parenting model wherein parents more likely to follow their internalized models delineating how their parents act (Cicchetti \& Toth, 1998). However, this mechanism cannot explain why neglect history did not beget child neglect. It is theorized that the intergenerational continuity of child maltreatment may involve the children learning and legitimizing their parent's philosophies and practices of discipline and using them to guide their own parenting practices (Simons, Whitbeck, Conger, \& Chyi-In, 1991). If this theory is true, neglected children may not learn or legitimize the manner in which they are treated by their parents. Further studies are essential to confirm the differential mechanism of intergenerational continuity of child maltreatment by its subtypes.

This study adds to the literature that the association between childhood abuse history and child maltreatment was mediated by mental health symptoms, specifically, dissociated and depressive symptoms in Japan. This is consistent with the previous study demonstrating that a mother or partner treated for mental illness or depression mediates the association between childhood abuse history and child maltreatment (Dixon, Browne, \& Hamilton-Giachritsis, 2005). In addition, dissociated symptoms were also reported as the mediator of intergenerational continuity of child maltreatment (Egeland \& Susman-Stillman, 1996). Both previous studies did not assess the several mental health symptoms simultaneously; thus, it was hard to speculate which mental health symptom was more likely to mediate the intergenerational continuity of child maltreatment. Our study revealed that dissociated and depressive symptoms, but not traumatic symptoms, showed a similar mediating effect for childhood abuse history and child maltreatment. Further studies warrant elucidating the different mechanism of mental health symptoms mediating the impact of childhood abuse history and child maltreatment.

Several limitations of this study need to be acknowledged. First, as childhood abuse history and DV were assessed retrospectively and were self-reported, the measurement of these experiences might include recall bias and might be affected by mental health symptoms (i.e., a woman with childhood abuse history might not be able to remember her childhood abuse history owing to dissociation while responding). Second, to assess childhood abuse history, DV, and child maltreatment, standard scales were not used, although they were referenced for the development of other such measurements. Further research is warranted to establish the validity and reliability of the scale used in this study. Third, the study sample was a convenient one, with weighted mothers who have lived with a violent husband or partner. Thus, it is hard to generalize the results even to a Mother-Child Home, owing to a sampling bias. Future research using the general population must be conducted to confirm the intergenerational continuity of child maltreatment.

Nonetheless, this study suggested the importance of mental health symptoms, especially dissociated and depressed symptoms, as possible mediators of the intergenerational continuity of child maltreatment, which might be useful to break the cycle of child maltreatment. Professional support by psychiatrists or psychologists addressing dissociated and depressed symptoms may be the effective way to weaken the link between childhood abuse history and child physical or psychological abuse. As child neglect was not associated with childhood abuse history, but associated with mental symptoms, addressing mental symptoms may be effective in preventing child neglect directly.

\section{Conclusion}

In conclusion, the intergenerational continuity of child physical and psychological abuse, but not neglect, was confirmed in Japan. Mental health symptoms, mainly dissociated and depressive symptoms, are considered mediators of the link between childhood abuse history and child physical and psychological abuse. Treatment of mental symptoms, especially dissociated and depressive symptoms, might be the effective way to break the cycle of child maltreatment. 


\section{Acknowledgements}

This research is supported by Research on Self-support of Victims of Domestic Violence and its Support, in Research on Children and Families, Health and Labor Sciences Research Grants from Ministry of Health, Labor, and Welfare (PI: Tomoko Ishii) and Research Grants from Ministry of Health, Labour, and Welfare (H23-Seisaku-Ippan-005).

\section{References}

Baron, R. M., \& Kenny, D. A. (1986). The moderator-mediator variable distinction in social psychological research: conceptual, strategic, and statistical considerations. J Pers Soc Psychol, 51(6), 1173-1182.

Bernstein, D. P., Fink, L., Handelsman, L., Foote, J., Lovejoy, M., Wenzel, K., . . Ruggiero, J. (1994). Initial reliability and validity of a new retrospective measure of child abuse and neglect. Am J Psychiatry, 151(8), 1132-1136.

Briere, J., \& Runtz, M. (1988). Multivariate correlates of childhood psychological and physical maltreatment among university women. Child Abuse Negl, 12(3), 331-341. http://dx.doi.org/10.1016/0145-2134(88)90046-4

Brown, J., Cohen, P., Johnson, J. G., \& Salzinger, S. (1998). A longitudinal analysis of risk factors for child maltreatment: findings of a 17-year prospective study of officially recorded and self-reported child abuse and neglect. Child Abuse \& Neglect, 22(11), 1065-1078. http://dx.doi.org/10.1016/S0145-2134(98)00087-8

Center for Child Abuse Prevention. (1999). General Household Survey: Current Status of Mother's Child Maltreatment. Tokyo: Report of Grant aid for child care, Welfare and Medical Service, Fiscal Year 1998 (Japanese).

Cicchetti, D., \& Toth, S. L. (1998). Perspectives on research and practice in developmental psychopathology. In W. Damon, I. E. Sigel \& K. A. Renninger (Eds.), Handbook of child psychology. Vol 4: child psychology in practice. New York: John Wiley \& Sons, Inc.

Crouch, J. L., Milner, J. S., \& Thomsen, C. (2001). Childhood physical abuse, early social support, and risk for maltreatment: current social support as a mediator of risk for child physical abuse. Child Abuse Negl, 25(1), 93-107. http://dx.doi.org/10.1016/S0145-2134(00)00230-1

Dixon, L., Browne, K., \& Hamilton-Giachritsis, C. (2005). Risk factors of parents abused as children: a mediational analysis of the intergenerational continuity of child maltreatment (Part I). J Child Psychol Psychiatry, 46(1), 47-57. http://dx.doi.org/10.1111/j.1469-7610.2004.00339.x

Edwards, V. J., Holden, G. W., Felitti, V. J., \& Anda, R. F. (2003). Relationship between multiple forms of childhood maltreatment and adult mental health in community respondents: results from the adverse $\begin{array}{llllll}\text { childhood experiences study. Am } J \text { Psychiatry, } & \text { 160(8), }\end{array}$ http://dx.doi.org/10.1176/appi.ajp.160.8.1453

Egeland, B., \& Susman-Stillman, A. (1996). Dissociation as a mediator of child abuse across generations. Child Abuse Negl, 20(11), 1123-1132. http://dx.doi.org/10.1016/0145-2134(96)00102-0

Ertem, I. O., Leventhal, J. M., \& Dobbs, S. (2000). Intergenerational continuity of child physical abuse: how good is the evidence? Lancet, 356(9232), 814-819. http://dx.doi.org/10.1016/S0140-6736(00)02656-8

Fantuzzo, J., Boruch, R., Beriama, A., Atkins, M., \& Marcus, S. (1997). Domestic violence and children: prevalence and risk in five major U.S. cities. J Am Acad Child Adolesc Psychiatry, 36(1), 116-122. http://dx.doi.org/10.1097/00004583-199701000-00025

Finkelhor, D., Ormrod, R. K., \& Turner, H. A. (2007). Poly-victimization: a neglected component in child victimization. Child Abuse Negl, 31(1), 7-26. ttp://dx.doi.org/10.1016/j.chiabu.2006.06.008

Fujiwara, T., Okuyama, M., Izumi, M., \& Osada, Y. (2010). The impact of childhood abuse history and domestic violence on the mental health of women in Japan. Child Abuse \& Neglect, 34, 267-274. http://dx.doi.org/10.1016/j.chiabu.2009.07.007

Horwitz, A. V., Widom, C. S., McLaughlin, J., \& White, H. R. (2001). The impact of childhood abuse and neglect on adult mental health: a prospective study. J Health Soc Behav, 42(2), 184-201.

Hudson, W. W., \& McIntosh, S. R. (1981). The assessment of spouse abuse: Two quantifiable dimensions. Journal of Marriage and the Family, 43, 873-888.

Kaufman, J., \& Zigler, E. (1987). Do abused children become abusive parents? Am J Orthopsychiatry, 57(2), 
186-192. http://dx.doi.org/10.1111/j.1939-0025.1987.tb03528.x

Knutson, J. F. (1995). Psychological characteristics of maltreated children: putative risk factors and consequences. Aппи Rev Psychol, 46, 401-431. http://dx.doi.org/10.1146/annurev.ps.46.020195.002153

Newcomb, M. D., \& Locke, T. F. (2001). Intergenerational cycle of maltreatment: a popular concept obscured by $\begin{array}{llll}\text { methodological limitations. Child Abuse Negl, 25(9), 1219-1240. } & \end{array}$ http://dx.doi.org/10.1016/S0145-2134(01)00267-8

Rieker, P. P., \& Carmen, E. H. (1986). The victim-to-patient process: the disconfirmation and transformation of abuse. Am J Orthopsychiatry, 56(3), 360-370. http://dx.doi.org/10.1111/j.1939-0025.1986.tb03469.x

Ross, S. M. (1996). Risk of physical abuse to children of spouse abusing parents. Child Abuse Negl, 20(7), 589-598. http://dx.doi.org/10.1016/0145-2134(96)00046-4

Simons, R. L., Whitbeck, L. B., Conger, R. D., \& Chyi-In, W. (1991). Intergenerational transmission of harsh parenting. Developmental Psychology, 27, 159-171. http://dx.doi.org/10.1037/0012-1649.27.1.159

Steele, B., \& Pollack, C. (1968). A psyhiatric study of parents who abuse infants and small children. In R. Helfer \& C. Kempe (Eds.), The battered child syndrome (pp. 103-145). Chicago, IL: University of Chicago Press.

Tajima, E. A. (2000). The relative importance of wife abuse as a risk factor for violence against children. Child Abuse Negl, 24(11), 1383-1398. http://dx.doi.org/10.1016/S0145-2134(00)00194-0

Widom, C. S. (1989a). The cycle of violence. Science, 244(4901), 160-166. DOI: 10.1126/science.2704995

Widom, C. S. (1989b). Does violence beget violence? A critical examination of the literature. Psychol Bull, 106(1), 3-28. http://dx.doi.org/10.1037/0033-2909.106.1.3

Widom, C. S., DuMont, K., \& Czaja, S. J. (2007). A prospective investigation of major depressive disorder and comorbidity in abused and neglected children grown up. Arch Gen Psychiatry, 64(1), 49-56. http://dx.doi.org/10.1001/archpsyc.64.1.49

\section{(c) $\mathbf{E Y}$}

This work is licensed under a Creative Commons Attribution 3.0 License. 